\title{
Aetiology Of Pyrexia With Hepatosplenomegaly: Study Of 50 Cases In MMCH (Bangladesh)
}

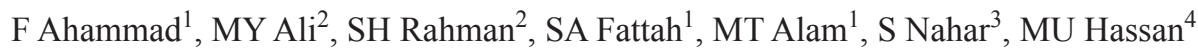

\begin{abstract}
Pyrexia with hepatosplenomegaly is a common problem in medical practice globally, specially in tropical countries. In Bangladesh several tropical diseases as well as hematological malignancies are responsible for such clinical syndrome. Again different tropical diseases vary in endemicity in different regions in Bangladesh. In Present study 50 hospitalized cases of pyrexia with hepatosplenomegaly of 15-50 years of age are included from 01.01.2002 to 30.06.2002 in MMCH to find out their aetiologies. Fever with only hepatomegaly, or with only splenomegaly or hepatosplenomegaly without fever was not included in this study. Duration of fever was two weeks to three months. $35(70 \%)$ cases were male and $15(30 \%)$ were female. $27(54 \%)$ cases were visceral leishmaniasis (kala-azar), $8(16 \%)$ malaria, 6 (12\%) Acute leukemia (ALL, AML), 3 (6\%) Lymphoma, 3(6\%) Enteric fever, 2(4\%) CML, 1(2\%) Disseminated TB. Although kala-azar and malaria are tow common causes of fever with hepatosplenomegaly, haematological malignancies and tuberculosis should be in mind.
\end{abstract}

\section{Introduction}

In Bangladesh, like other tropical countries in the world, pyrexia with hepatosplenomegaly is a common clinical problem ${ }^{1,2}$. Due to variation of endemicity of Malaria and Kala-azar (two common causes of such syndrome) in different regions in Bangladesh and due to less sensitivity of malarial parasite detection in blood film and also due to false positivity of Aldehyde test, medical practitioner's specially rural general practitioners suffer from dilemma to manage patients of pyrexia with hepatosplenomegaly. Some are overenthusiastic about malaria and kala-azar ignoring hematological malignancy. Direct Agglutination Test (DAT) test for kala-azar is only available in Institute of Epidemic Disease Control \& Research (IEDCR), Mohakhali, Dhaka.

1. Dr. Faruk Ahammad, FCPS (Medicine), Dr. Sk. Abdul Fattah, DTCD, FCPS (Medicine), Dr. Md. Towhid Alam, FCPS (Medicine), Assistant Professor, Dept. of Medicine, FMC, Faridpur.

2. Dr. Md. Yusuf Ali, FCPS (Medicine), Dr. Shah Habibur Rahman, FCPS (Medicine), Associate Professor, Dept. of Medicine, FMC, Faridpur.

3. Dr. Shamsun Nahar, FCPS (Radiotherapy), Assistant Professor, Dept. of Oncology, BSMMU.

4. Dr. Mahatab uddin Hassan, FCPS (Medicine), MRCP (UK), Professor, Dept. of Medicine, CMC, Chittagong.

Address of correspondence

Dr. Faruk Ahammad, FCPS (Medicine), Assistant Professor, Dept. of Medicine, FMC, Faridpur.

Phone: +88- 01817011894. E-mail: farukahammad26@yahoo.com
Leishmanian Donovani (LD) body detection by splenic puncture or bone marrow examination is possible in specialized centers. As a result diagnosis of visceral leishmaniasis (kala-azar) is difficult ${ }^{3,4}$. Detection of haematological malignancy is also difficult due to less availability of facility ${ }^{2}$. Aim and objective of this study was to find out the aetiologies of pyrexia with hepatosplenomegaly and to make a simple plan of investigations for easy and early diagnosis of such syndrome.

\section{Materials and Methods}

Total numbers of study people were fifty. Among them $35(70 \%)$ were male and $15(30 \%)$ female. Age ranging from 12 to 50 years. Study subjects were hospitalized patients in different medicine units of Mymensingh Medical College hospital. Study period was $1^{\text {st }}$ January 2002 to $30^{\text {th }}$ June 2002. All selected subjects for study had pyrexia with hepatosplenomegaly. Some had additional features like severe anaemia, jaundice, lymphadenopathy and bleeding manifestations. Patients of pyrexia with only splenomegaly or only hepatomegaly or hepatosplenomegaly without pyrexia were excluded from the study. A detailed history and clinical examination of each patient was done. Special attention regarding temperature chart maintenance, spleen and liver examination and measurement was given.

Investigations were done according to history and clinical examination findings. All patients were advised 
for total and differential count, hemoglobin level, erythrocyte sedimentation rate, study for peripheral blood film and platelet count. Blood for malarial parasite (thick and thin film), Aldehyde test, Widal test, Monteux test and X-ray chest P/A view were done according to suspected individual. Lymph node biopsy was done where lymphadenopathy were found. Bone marrow examination with special emphasis about LD body was done where applicable. Splenic puncture was done in selected cases. DAT, ELISA, culture for Kalaazar were not done due to lack of facility. But ICT for Kala-azar was done in suspected cases of Kala-azar with positive Aldehyde test.

\section{Results}

Table I: Aetiological distribution of study subjects $(\mathrm{n}=50)$

\begin{tabular}{lcc}
\hline Disease & No. of cases & Percentage \\
\hline Visceral leishmaniasis & 27 & $54 \%$ \\
Malaria & 8 & $16 \%$ \\
Acute Leukaemia & 6 & $12 \%$ \\
Lymphoma & 3 & $6 \%$ \\
Enteric fever & 3 & $6 \%$ \\
CML & 2 & $4 \%$ \\
Disseminated TB & 1 & $2 \%$ \\
\hline Total=(n) & 50 & $100 \%$ \\
\hline
\end{tabular}

Table I shows kala-azar 27(54\%) cases, malaria 8(16\%) cases, acute leukaemia (AML-4, ALL-2) 6(12\%) cases, lymphoma-3 (6\%) cases, CML-2(4\%) cases, enteric fever $3(6 \%)$ and disseminated TB $1(2 \%)$ cases were found.
Table II: Distribution of Age according to aetiology $(\mathrm{n}=50)$

\begin{tabular}{lcccc}
\hline & \multicolumn{4}{c}{ Age distribution (in years) } \\
\cline { 2 - 5 } Diseases (n=50) & $12-20$ & $21-30$ & $31-40$ & $41-50$ \\
\hline Kala- Azar (27) & 3 & 14 & 8 & 2 \\
Malaria (8) & 1 & 4 & 2 & 1 \\
AML (4) & 2 & 2 & - & - \\
ALL (2) & 2 & - & - & - \\
Lymphoma (3) & 1 & 2 & - & - \\
CML (2) & - & - & 1 & 1 \\
Enteric fever (3) & 2 & 1 & - & - \\
Disseminated TB (1) & - & 1 & - & - \\
\hline Total (50) & 11 & 24 & 11 & 4 \\
\hline
\end{tabular}

Table II shows majority cases $(51.85 \%)$ of kala-azar were 21-30 years of age group. Similarly malaria and haematological malignancy were maximum in the same age group.

Table III: Distribution of Sex according to aetiology $(\mathrm{n}=50)$

\begin{tabular}{lcc}
\hline Disease & Male & Female \\
\hline Kala-azar & 20 & 7 \\
Malaria & 5 & 3 \\
AML & 3 & 1 \\
ALL & 1 & 1 \\
Lymphoma & 2 & 1 \\
CML & 1 & 1 \\
Enteric fever & 2 & 1 \\
Disseminated TB & 1 & 0 \\
\hline Total=(n-50) & 35 & 15 \\
\hline
\end{tabular}

Table III shows male affected more than female in kalaazar, malaria and haematological malignancies. 
Table IV: Degree of hepatomegaly (HP) in relation to aetiology $(n=50)$

\begin{tabular}{llll}
\hline Disease & Mild HP & Moderate HP & Marked HP \\
& $(<5 \mathrm{~cm})$ & $(5-10 \mathrm{~cm})$ & $(>10 \mathrm{~cm})$ \\
\hline Kala- azar(n=27) & $20(74 \%)$ & $7(26 \%)$ & - \\
Malaria(n=8) & $6(75 \%)$ & $2(25 \%)$ & - \\
AML $(\mathrm{n}=4)$ & $2(50 \%)$ & $2(50 \%)$ & - \\
ALL $(\mathrm{n}=2)$ & $1(50 \%)$ & $1(50 \%)$ & - \\
Lymphoma(n=3) & $1(33.33 \%)$ & $1(66.66 \%)$ & \\
CML(n=2) & - & - & - \\
Enteric fever(n=3) & $3(100 \%)$ & - & - \\
Disseminated TB $(\mathrm{n}=1)$ & $1(100 \%)$ & - & $2(100)$ \\
\hline Total=(n-50) & $34(68 \%)$ & $14(28 \%)$ & - \\
\hline
\end{tabular}

Table IV shows $74 \%$ of Kala-azar and $75 \%$ of malaria cases had mild hepatomegaly, rest had moderate to marked hepatomegaly. Two cases of marked hepatomegaly were due to CML.

Table V: Degree of splenomegaly in relation to aetiology $(n=50)$

\begin{tabular}{llll}
\hline Disease & $\begin{array}{l}\text { Mild } \\
\text { splenomegaly } \\
(<2 \mathrm{~cm})\end{array}$ & $\begin{array}{l}\text { Moderate } \\
\text { splenomegaly }\end{array}$ & $\begin{array}{l}\text { Marked } \\
\text { splenomegaly }\end{array}$ \\
\hline Kala- azar (n=27) & $5(18.51 \%)$ & $20(74.02 \%)$ & $2(7.40 \%)$ \\
Malaria (n=8) & $1(12.5 \%)$ & $5(62.5 \%)$ & $2(25 \%)$ \\
AML (n=4) & $2(50 \%)$ & $2(50 \%)$ & - \\
ALL (n=2) & $1(50 \%)$ & $1(50 \%)$ & - \\
Lymphoma $(\mathrm{n}=3)$ & $1(33.33 \%)$ & $2(66.66 \%)$ & - \\
CML (n=2) & - & - & $2(100 \%)$ \\
Enteric fever $(\mathrm{n}=3)$ & $3(100 \%)$ & - & - \\
Disseminated TB $(\mathrm{n}=1)$ & $1(100 \%)$ & - & $6(12 \%)$ \\
\hline Total=50 & $14(28 \%)$ & $30(60 \%)$ & \\
\hline
\end{tabular}

Table V shows $74.02 \%$ of Kala-azar cases and $62.50 \%$ of malaria cases had moderate splenomegaly. $50 \%$ of laeukemia and $50 \%$ of lymphoma cases had moderate splenomegaly and $100 \%$ of CML cases had marked splenomegaly.

\section{Discussion}

In tropical countries like Bangladesh pyrexia with hepatosplenomegaly is a common clinical problem ${ }^{1,2}$.
In our country malaria and kala-azar are common infectious diseases for such clinical syndrome. But malignancy especially leukaemia and lymphoma are also second important causes of pyrexia with hepatosplenomegaly in Bangladesh. In some districts like Mymensingh, Sherpur, Tangail, Jamalpur, Netrokona, Kishorganj, Sirajgonj and Rajshahi of Bangladesh, kala-azar is becoming a rising problem. In my observation in hospitalized patients of Mymensingh Medical College Hospital, patients of pyrexia with hepatosplenomegaly are being handled by different physicians in different ways, specially at rural health centers. Some are overenthusiastic about the diagnosis of kala-azar ignoring old existent problem malaria. Again some are limited only to malaria and kala-azar forgetting other causes like leukaemia or lymphoma for such a clinical problem. So, my present study was done for showing the actual status of causes of such a common clinical problem together with making a simple plan of early diagnosis and management.

In my study, the most common causes were kala-azar 27(54\%), malaria 8(16\%), acute leukaemia (AML-4+ ALL-2=6) (12\%), lymphoma-3 (6\%), CML-2 (4\%), enteric fever-3 (6\%) and disseminated TB-1 (2\%) cases.

"Internal evaluation of the program activities for control of visceral leishmaniasis in Bangladesh" jointly organized by NIPSOM, WHO and UNDP (1987-88) has shown that resurgence of kala-azar since 1981 in Bangladesh has become a great health problem in Mymensingh, Sirajgonj and Pabna where the incidence is $0.33,0.41$ and 0.51 respectively ${ }^{1}$. In my study kalaazar was the most common causes of pyrexia with hepatosplenomegaly and percentage is more than malaria. So it is consistent with the comment and findings of NIPSOM, WHO and UNDP study.

One study by Mahmuda $\mathrm{K}^{2}$ revealed common causes of hepatosplenomegaly in children as ALL (20\%), kalaazar (14\%), hereditary hemolytic anaemia (14\%), portal hypertension (8\%), disseminated TB (7\%), and enteric fever $(7 \%)$. In that study ALL was the commonest cause of hepatosplenomegaly which is different from my present study. It may be due to her study on children and cases of hepatosplenomegaly with or without pyrexia were included in her study. Moreover that study was done in 1996. By this time the incidence of kala-azar has risen. Another study done by Sarkar J 3 had found common causes of hepatosplenomegaly as CML (24\%), cirrhosis of liver (20\%), kala-azar (10\%). My study differs also from the study of Sarkar J probably due to different place of study and also his study of the cases with or without pyrexia. 
Another study was done by Mazharul IAEM ${ }^{4}$ on hospitalized 50 cases of pyrexia with hepatosplenomegaly who found kala-azar in $48 \%$ cases malaria in $20 \%$, acute leukaemia $16 \%$, lymphoma $6 \%$, CML $4 \%$, enteric fever $4 \%$ and disseminated TB 2\% cases. My present study was almost consistent with that study but I found kala-azar in 54\% cases, which is important and matter of concern that the kala-azar is spreading enormously and has become a giant health problem.

In my study, age groups were selected between 12-50 years. Maximum patients (48\%) were in the age of 2130 years. Most of the kala-azar patients $(51.85 \%)$ were in 21-30 years and $29.62 \%$ were in the age of $31-40$ years. Acute leukaemia were maximum in the age of 12-30 years where as CML were $>30$ years of age. Enteric and disseminated TB was in young age group. In one study over hospitalized patients Islam $\mathrm{S}^{5}$ found highest incidence of kala-azar was in 13-19 age group (32\%) and Mazharul IAEM ${ }^{4}$ found most of the kalaazar patients in 21-30 years age group. Both study as well as my present study found that kala-azar is mostly in 13-30 years age group.

"Internal evaluation of the program activities for control of visceral leishmaniasis in Bangladesh" had found that incidence of kala-azar in male was 3 times more than female (male: female $=3: 1$ ). My present finding is similar as that finding. I found 20 patients of male and 7 patients of female among 27 cases of kalaazar. Sarkar J, Mahmuda K, Mazharul IAEM all in their study found male preponderance of cases with hepatosplenomegaly.

In my study $68 \%$ out of 50 suffered from mild hepatomegaly, $28 \%$ with moderate hepatomegaly. Two patients out of 50 patients had marked hepatomegaly and both suffered from CML. My findings were almost similar in percentage to the study of Mahmuda K, Thakur $\mathrm{CP}^{6}$, Islam S, Sundar $\mathrm{S}^{7}$, Elias $\mathrm{M}$, et $\mathrm{al}^{8}$ and Mazharul IAEM. $75 \%$ cases of malaria and $100 \%$ cases of enteric fever and disseminated TB had mild hepatomegaly. In kala-azar series $74.02 \%$ cases had moderate splenomegaly which is consistent with the findings by Islam S. But Mahmuda $\mathrm{K}$ found moderate splenomegaly in Kala-azar in only $28.5 \%$ cases. This is different from my findings probably due to small number of samples in kala-azar series and also due to her study over child age group.

\section{Conclusion}

In MMCH usually admitted patients are from different upazillas of Mymensingh, Jamalpur, Tangail, Sherpur, and Kishorganj. In these districts Kala-azar has become a matter of concern. But other causes of pyrexia with hepatosplenomegaly like malaria and haemopoeitic malignancies should keep in mind.

\section{References}

1. "Internal evaluation of the programme activities for control of visceral leishmaniasis in Bangladesh" - ICP-PDP 002, RAS/85 (02) A/01/19/ NIPSOM/WHO/UNDP; 1987 - 88.

2. Mahmuda K. Etiological study of hepatosplenomegaly in hospitalized children (A study of 100 cases) [Dissertation]. [Dhaka]: BCPS; 1996.

3. Sarkar J. An etiological study of hepatosplenomegaly in adult [Dissertation]. [Dhaka]: BCPS; 1983.

4. Mazharul IEAM. Pyrexia with hepatosplenomegaly - presentation and diagnosis [Dissertation]. [Dhaka]: BCPS; 1998.

5. Islam S. Diagnostic approach to Kala-azar in clinically suspected cases, a study of 50 cases [Dissertation]. [Dhaka]: BCPS; 1996.

6. Thakur CP. Epidemiology of Bihar kala-azar. Trans \& Soc Trop Med Hyg. 1984;78:391-8.

7 Sundar S. Availability of miltefosine for the treatment of Kalaazar in India. Bull World Health Organ. 2005;83(5):394-395.

8. Elias M, Rahman A, Khan NI. Visceral leishmaniasis and its control in Bangladesh. Bull World Health Organ. 1989;67(1):43-9. 